\title{
Assessment of Water Quality of Major Tributaries in Seoul using Water Quality Index and Cluster Analysis
}

\author{
Jinhyo Lee ${ }^{1,2 \odot} \cdot$ Hyunju Ha $^{1 \odot} \cdot$ Manho Lee ${ }^{1 \odot} \cdot$ Mokyoung Lee $^{1 \odot} \cdot$ Taeho Kim $^{2 \odot}$. $^{\circ}$ \\ Yoonkyung $\mathrm{Cha}^{2 \odot} \cdot$ Jayong $\mathrm{KoO}^{2,+\odot}$
}

'Water Environment Research Department, Seoul Metropolitan Government Research Institute of Public Health and Environment ${ }^{2}$ Department of Environmental Engineering, University of Seoul

(Received August 19, 2020; Revised October 1, 2020; Accepted October 5, 2020)

Objectives: 17 water quality measurement networks (WQMNs, tributaries) in Seoul were analyzed by using NSFWQI and cluster analysis to provide basic data for future river water quality management so that citizens could easily and comprehensively understand the water quality information on the rivers in Seoul.

Methods: For the past 3 years (2015 2017), in order to estimate WQI, 9 items, DO (\% sat), Fecal coliform, pH, BOD, Temperature change (TC), TP, $\mathrm{NO}_{3}^{-}$, Turbidity and Total solids, were selected from among the 19 water quality data measurement items produced monthly from 17 WQMNs in Seoul. WQI was derived and graded using NSFWQI and cluster analysis was performed using Ward Linkage Method, SOM (Self Organizing Map).

Results and Discussion: Water quality of most water quality monitoring networks was BOD II grade (slightly good) or higher and TP III grade (normal) or higher according to the standard of water quality and water ecosystem river living environment, and NSFWQI was also 64 (Medium) 89 (Good). All showed good water quality. NSFWQI does not show a significant difference by season, so it is believed that it is affected by anthropogenic sources rather than seasonal effects. As a result of examining the correlation between NSFWQI and water quality level according to environmental standards, it was confirmed that $\mathrm{R}^{2}$ has a relatively good correlation with 0.78 , and there is no clear difference between the two groups, and through this, it was found that the currently implemented water quality rating system and NSFWQI are well matched. As a result of cluster analysis using ward linkage method and SOM for 17 WQMNs, it was largely divided into 6 groups according to water quality characteristics.

Conclusions: It is important to manage pollution sources to systematically manage river water quality as a water resource. It is therefore expected that by converting from the complicated and various water quality information such as is found in this study into a simple water quality index and grouping, the river water quality can be easily understood and can be utilized in the future as basic data for water quality management in Seoul.

Keywords: Water Quality Measurement Networks, WQI, Cluster Analysis, Ward Linkage, SOM

The Korean text of this paper can be translated into multiple languages on the website of http://jksee.or.kr through Google Translator. 


\title{
연구논문
}

\section{수질지수와 군집분석을 활용한 서울시 주요 하천 수질평가}

\author{
이진효 ${ }^{1,2 \odot} \cdot$ 하현주 $^{1 \odot} \cdot$ 이만호 $^{1 \odot} \cdot$ 이목영 $^{1 \odot} \cdot$ 김태호 $^{2 \odot} \cdot$ 차윤경 $^{2 \odot} \cdot$ 구자용 $^{2+\oplus}$ \\ ${ }^{1}$ 서울특별시보건환경연구원 물환경연구부 \\ ${ }^{2}$ 서울시립대학교 환경공학부
}

목적: 서울시내 17 개 국가 물환경측정망(지천 지점)을 대상으로, 시민들이 쉽게, 종합적으로 서울시 하천수질정보 를 이해할 수 있도록 매월 측정된 수질자료로부터 수질지수를 도출하고, 이와 함께 수질측정망 수질특성을 활용한 군집분석을 실시하여 수질의 상태를 종합적으로 평가하는 등 향후 서울시 하천수질관리를 위한 기초자료를 제공 하고자 하였다.

방법: 2015 2017년 최근 3년 동안 서울시내 17개 국가 물환경측정망에서 매월 생산되는 수질자료(19개 항목) 중 수질지수 산정을 위해 $\mathrm{DO}$ (\% sat), 분원성대장균군, $\mathrm{pH}, \mathrm{BOD}$, 수온변화, $\mathrm{TP}, \mathrm{NO}_{3}^{-}$, 탁도, $\mathrm{TS}$ 등 9 개 수질항목을 이용하여 NSFWQI 수질지수를 산정하였고, 수질지수를 활용하여 계층분석방법 중의 하나인 Ward 연결법(Ward linkage method)과 차원축소(Dimensionality reduction) 및 군집화를 동시에 수행하는 SOM을 이용하여 군집화를 실 시하였다.

결과 및 토의: 최근 3 년간 17 개 국가 물환경측정망의 수질을 살펴보면, 대부분의 수질측정망 수질은 평균적으로 수 질 및 수생태계 하천생활환경기준에 따라 BOD $\Pi$ 등급(약간 좋음) 이상, TP III등급(보통) 이상으로 나타났고, 수질 지수 또한 64 (Medium) 89 (Good)으로 나타나는 등 전반적으로 모두 양호한 수질을 보였으며, NSFWQI 수질지수 는 계절별로 큰 차이를 보이지 않아, 계절적인 영향보다는 인위적인 오염원 등에 영향을 크게 받는 것으로 판단된 다. NSFWQI 수질지수와 환경기준에 따른 수질등급과의 상관성을 살펴본 결과, $\mathrm{R}^{2}$ 이 0.78 로 비교적 높은 상관관계 를 갖고, 두 그룹간의 뚜렷한 차이를 볼 수 없는 등 현재 시행되는 수질등급체계와 NSFWQI 수질지수는 매칭이 잘 되는 것으로 판단된다. 17 개 국가 물환경측정망을 대상으로 Ward 연결법 및 $\mathrm{SOM}$ 을 이용한 군집분석 결과, 수 질특성에 따라 크게 6 개의 그룹으로 나누어졌다.

결론 : 하천으로의 오염물질 유입은 그 종류와 양이 증가되고 있으며, 이러한 상황 속에서 하천을 수자원으로서 지 속적으로 활용하기 위해서는 하천수질을 체계적으로 관리하기 위한 오염원 관리가 무엇보다 중요하다. 본류 및 지 류·지천의 오염원 관리를 위해 설치된 수질측정망에서는 다양한 수질항목들을 측정하고 있지만, 개별항목을 분석 하는 것만으로는 체계적이고 종합적으로 하천수질을 평가하는 것은 어렵다. 따라서 본 연구와 같이 하천수질상태 를 쉽게 이해하기 위해서 복잡하고 다양한 수질정보를 간단한 지표로 변환한 수질지수와 함께 수질특성에 따른 군 집화 결과는 향후 서울시 하천수질관리를 위한 기초자료로 활용될 수 있을 것으로 기대한다.

주제어 : 수질측정망, 수질지수, 계층적 군집분석, 와드연결법, 자기조직화지도

\section{1. 서 론}

하천수질을 체계적으로 관리하기 위해서는 오염원 관리 가 무엇보다 중요한데, 이를 위해 본류 자체뿐만 아니라 본 류로 향하는 지류·지천의 오염원 관리가 필요하다. ${ }^{1)}$ 따라서 하천, 호소 등 공공수역에 대한 수질현황 파악 및 환경정책 수립을 위한 기초자료 확보를 위해 국가 및 지자체에서는 물환경측정망을 운영하고 있으며, 우리 연구원에서도 국가 물환경측정망으로서 17 개 주요 지천을 수질측정망으로 지
정하여 운영하고 있다. 이에 따라 매월 방대한 양의 수질측 정망 데이터가 생산되고 있는데, 문제는 각 항목별 데이터 를 개별적으로 분석하는 것만으로는 상시 변동하는 하천의 수질을 종합적으로, 쉽게 이해하기는 어렵다는 것이다. ${ }^{2)}$ 특 히 물환경에 대한 시민들의 관심증가로 인하여 시민들의 알 권리 충족에 부합될 수 있는 형태의 이해하기 쉽고, 종합적 인 수질정보를 제공해야 할 필요성이 높아지고 있다.

최근에 수질지수(Water quality index, WQI)와 군집분석 (Cluster analysis)을 함께 이용하여 하천수질을 쉽게 이해하고, 
수질의 상태를 과학적으로 평가하기 위한 연구사례가 증가 하고 있다. ${ }^{3,4)}$ 우선 수질지수는 방대한 수질자료를 수질지수 로 전환하여 간단한 등급(점수)으로 표현함으로써, 현재 하 천의 수질상태를 종합적으로 파악하고, 하천수질의 추세파 악, 수계간 체계적인 수질비교 등 하천수질관리 관련 정책 효과 및 예측을 쉽게 할 수 있다. 동시에 비전문가 시민들도 복잡한 수질상태를 쉽게 이해할 수 있도록 하는 도구가 된 다. 수질지수를 구하는 방법에는 Weight arithmetic water quality index (WAWQI), National sanitation foundation water quality index (NSFWQI), Canadian council of ministers of the environment water quality index (CCMEWQI), Oregon water quality index (OWQI) 등 연구주체, 수질항목, 수질기 준, 유역특성 등에 따라 다양하다. ${ }^{2,5)}$ 한편 군집분석은 각 개 체에 대해 관측된 여러 개의 값들을 이용하여 유사한 성격 을 가지는 몇 개의 군집으로 집단화하고, 형성된 군집들의 특성 및 관계를 분석하는 다변량분석 기법 중의 하나로서, 크게 계층적 군집(Hierachical), 분할적 군집(Partitioning), 혼 합분포군집(Mixture distribution)이 있으며, 최근에는 비계층 적 군집분석의 하나인 자기조직화지도(Self organising map, $\mathrm{SOM})$ 방법도 많이 활용되고 있다.)

이에 본 연구에서는 서울시내 17 개 국가 물환경측정망(지 천 지점)을 대상으로, 시민들이 쉽게, 종합적으로 서울시 하 천수질정보를 이해할 수 있도록 매월 측정된 수질자료로부 터 수질지수를 도출하고, 이와 함께 수질측정망 수질특성을 활용한 군집분석을 실시하여 수질의 상태를 종합적으로 평 가하는 등 향후 서울시 하천수질관리를 위한 기초자료를 제 공하고자 하였다.

\section{2. 연구방법}

\section{1. 자료수집}

본 연구에서는 2015 2017년 최근 3년 동안 서울시내 17개
국가 물환경측정망에서(Fig. 1) 매월 생산되는 수질자료(19 개 항목) 중 수질지수 산정을 위해 $\mathrm{DO}$, 분원성대장균군, $\mathrm{pH}$, $\mathrm{BOD}$, 수온변화, $\mathrm{TP}, \mathrm{NO}_{3}^{-}$, 탁도, $\mathrm{TS}$ 등 9개 수질항목을 선정 하였다. 또한 각 수질항목은 수질오염공정시험기준(Notice of National Institute of Environmental Research No. 2017-57) (National Institute of Environmental Research (Korea), 2017) ${ }^{7}$, 먹는물수질공정시험기준(Notice of National Institute of Environmental Research No. 2017-19)(National Institute of Environmental Research (Korea), 2017) ${ }^{8}$ 에 따라 분석하였다.

\section{2. 분석방법}

본 연구에서 사용한 수질지수는 미국보건재단(NSF, National Sanitation Foundation)에서 개발한 NSFWQI (National Sanitation Foundation Water Quality Index)이며, 이를 통해 도출된 수질 지수는 Table 2와 같이 등급화하였다. NSFWQI 수질지수는 약 142 명 전문가들 집단에서의 의견을 델파이기법(Delphi)을 이용하는 등 미국 전역의 수질전문가 상당수의 의견을 조합해 항목별 가중치를 산출하고 적용함으로써 수질항목에 대한 선택과 하부지수 및 중요도에 대한 주관성을 줄일 수 있었다. 그 결과 전체 35 개 수질항목 중에서 NSFWQI에 적용된 수질 평가항목은 수온변화, $\mathrm{pH}, \mathrm{DO}(\% \mathrm{sat}), \mathrm{BOD}_{5}, \mathrm{NO}_{3}-\mathrm{N}, \mathrm{PO}_{4}-\mathrm{P}$, 분원성대장균, TS (Total Solid), 탁도 등 총 9개 항목으로 결정되었다. 또한 각 항목별 가중치는 Table1과 같으며, 특히 하천수질관리 측면에서 필수 점검항목인 $\mathrm{DO}, \mathrm{BOD}$, 대장균 군 등 상대적 중요도가 높은 항목들에 대해서 더 높은 가중치 가 부여되었다. ${ }^{9} \mathrm{NSFWQI는} \mathrm{비교적} \mathrm{계산이} \mathrm{간단하고,} \mathrm{재현성}$ 이 있으며, 비전문가도 쉽게 수질변화를 파악하고 활용할 수 있는 특징을 갖고 있어, 미국뿐만 아니라 유럽, 아시아 등지에서 널리 활용되고 있다. 수질지수를 구하는 공식은 Eq. (2.1)과 같으며 ${ }^{10,11)}$, 특히 계산에 필요한 측정항목 중 직접적으로 구할 수 없는 DO (\% sat), TS의 경우 Eq. (2.2) Eq. (2.5)와 같이 문헌(사이트), 실험 등에 제시된 관계식 등을

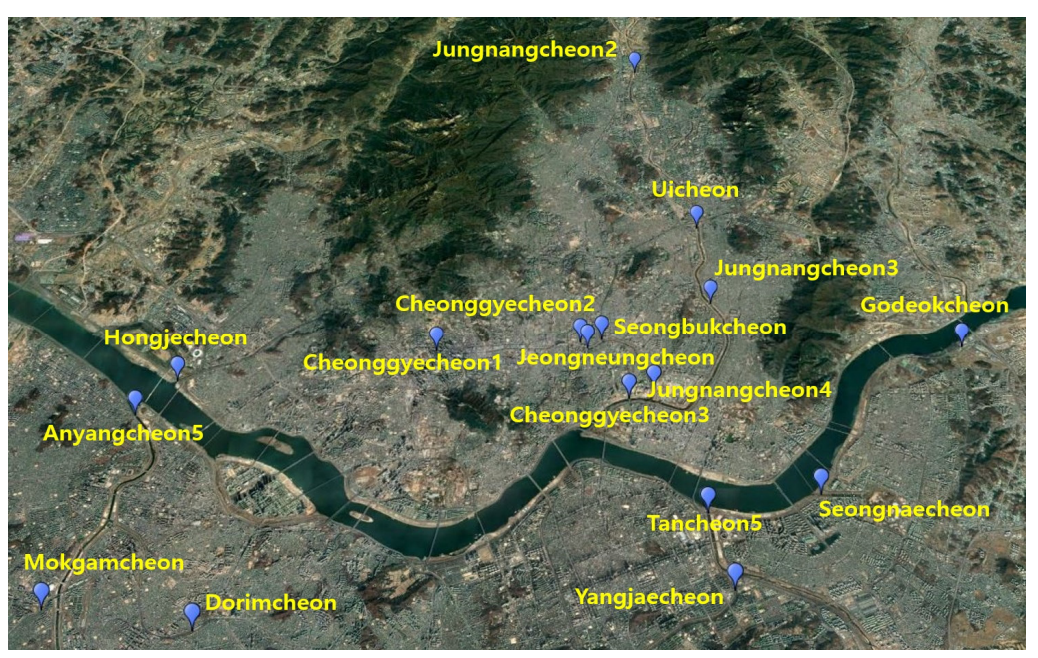

Fig. 1. 17 water quality monitoring networks in Seoul. 
Table 1. Water quality parameter and weight.

\begin{tabular}{cc} 
Parameters & Weight \\
\hline Dissolved Oxygen (\% sat) & 0.17 \\
\hline Fecal Coliform & 0.16 \\
\hline $\mathrm{pH}$ & 0.11 \\
\hline Biochemical Oxygen Demand & 0.11 \\
\hline Temperature Change (TC) & 0.10 \\
\hline Total Phosphate & 0.10 \\
\hline Nitrates & 0.10 \\
\hline Turbidity & 0.08 \\
\hline Total Solids (TS) & 0.07
\end{tabular}

활용하여 수질지수를 도출하였다. ${ }^{12-14)}$

$W Q I=\sum_{i=1}^{n} Q_{i} W_{i}$

$\mathrm{Q}_{\mathrm{i}}$ : sub-index for ith water quality parameter rating scale, sub index

$\mathrm{W}_{\mathrm{i}}$ : weight associated with ith water quality parameter

$\mathrm{n}$ : number of water quality parameters

$$
\begin{aligned}
& D O(100 \% \text { sat })=14.59-0.3955 T+0.0072 T^{2}-0.0000619 T^{3} \\
& D O(\% \text { sat })=\frac{D O}{D O(100 \% \text { sat })} \\
& \ln (T S S)=1.32 \times \ln (N T U)+0.15 \\
& T D S=k \times E C
\end{aligned}
$$

DO $(100 \%$ sat $)(\mathrm{mg} / \mathrm{L})$ : saturated DO concentration at the local temperature

DO $(\mathrm{mg} / \mathrm{L})$ : observed DO concentration

TSS (mg/L) : total suspended solids

TDS $(\mathrm{mg} / \mathrm{L})$ : total dissolved solids

$\mathrm{EC}(\mu \mathrm{S} / \mathrm{cm})$ : electrical conductivity

$\mathrm{k}$ : the ratio of TDS/EC (natural water $\mathrm{k}=0.65$, fresh water $\mathrm{k}=0.55$ )

또한 산정된 NSFWQI와 실제 환경정책기본법 시행령 제 2 호 환경기준에 ${ }^{15)}$ 의거 각 항목의 수질등급을 산정하여 NSFWQI
와의 비교·분석을 통해 연계 가능성을 살펴보았다. 이를 위 해 환경기준에 따른 수질등급을 산정하기 위한 항목으로는 NSFWQI 수질항목에 포함된 항목이면서, 동시에 명확하게 등급을 구분할 수 있는 항목으로, 9개 수질항목 중 BOD, TP, 분원성대장균군 3 항목을 이용하여 환경기준에 따른 수질등 급을 산정하였다.

계층적 군집분석은 개체간의 유사성 즉, 개체간의 거리 에 따라 다양한 정의가 가능하며, 군집간의 연결법(Single linkage method, Complete linkage method, Average linkage method, Centroid method, Ward linkage method)에 따라 군 집의 결과가 달라질 수 있다. ${ }^{6}$ 본 연구에서는 오픈소스 언 어인 R 3.5.2를 가지고 Fig.2 3과 같이 대표적 계층분석방 법 중의 하나인 Ward 연결법(Ward linkage method)과 차원 축소(Dimensionality reduction) 및 군집화를 동시에 수행하 는 SOM을 이용하여 군집화를 실시하였다. 여기서 Ward 연 결법은 Fig. 2에서 보듯이, 군집간의 거리에 따라 개체들을 연결하는 것이 아니라 군집 내의 오차제곱합(Error sum of sequare)에 기초하여 군집을 수행하는 것으로서 개체들을 하나의 군집으로 그룹화하여 발생하는 정보 손실(Loss of information)을 최소화하는 하는 방향으로 군집이 이루어진 다. 일반적으로 Ward 연결법은 비슷한 크기의 군집끼리 그 룹화되는 경향이 있으며, 다른 분석방법과 달리 노이즈 (noise)나 이상치(outlier)에 덜 민감한 장점이 있다. 그리고 비지도학습(Unsupervised learning) 신경회로망의 일종인 SOM 은 인공신경망(Artificial neural network, ANN)의 한 종류로 서, Fig.3과 같이 코호넨 네트워크(Kohonen network)에 근 간을 두고 있으며, 입력벡터(Input vector)를 훈련 집합에서 매칭(matching)이 되도록 가중치(weight)를 조정하는 인공신 경세포(Neuron) 격자에 기초한 자율학습의 한 방법이다. Fig.3에서 입력층(Input layer)은 입력벡터를 입력받는 층이 며, 가중치는 인공신경망에서 각 입력값들의 중요도를 나 타낸다. SOM은 원하는 출력값이 주어지지 않고 데이터 상 호간의 처리과정을 통해 자동적으로 군집을 구별짓는 등 ${ }^{16)}$, 입력변수의 위치 관계를 그대로 보존하면서 동시에 고차원

\begin{tabular}{|c|c|c|}
\hline WQI & Rating & Evaluation contents \\
\hline $91 \sim 100$ & Excellent & \multirow{2}{*}{$\begin{array}{l}\text { Water supplies with ratings falling in the good or excellent range would able to support a high } \\
\text { diversity of aquatic life and water would also be suitable for all forms of recreation, including those } \\
\text { involving direct contact with the water }\end{array}$} \\
\hline $71 \sim 90$ & Good & \\
\hline $51 \sim 70$ & Medium & $\begin{array}{c}\text { Water supplies achieving only an medium rating generally have less diversity of aquatic organisms } \\
\text { and frequently have increased algae growth }\end{array}$ \\
\hline $26 \sim 50$ & Bad & $\begin{array}{c}\text { Water supplies falling into the bad range are only able to support a low diversity of aquatic life and } \\
\text { are probably experiencing problems with pollution }\end{array}$ \\
\hline $0 \sim 25$ & Very bad & $\begin{array}{c}\text { A water supply with a very bad quality rating would not normally be considered acceptable for } \\
\text { activities involving direct contact with the water, such as swimming }\end{array}$ \\
\hline
\end{tabular}
의 데이터를 저차원(보통 2차원)의 지도 형태로 형상화하기 때문에 많은 양의 자료를 동일 시간대로 해석이 가능하며,

Table 2. Water quality rating. 


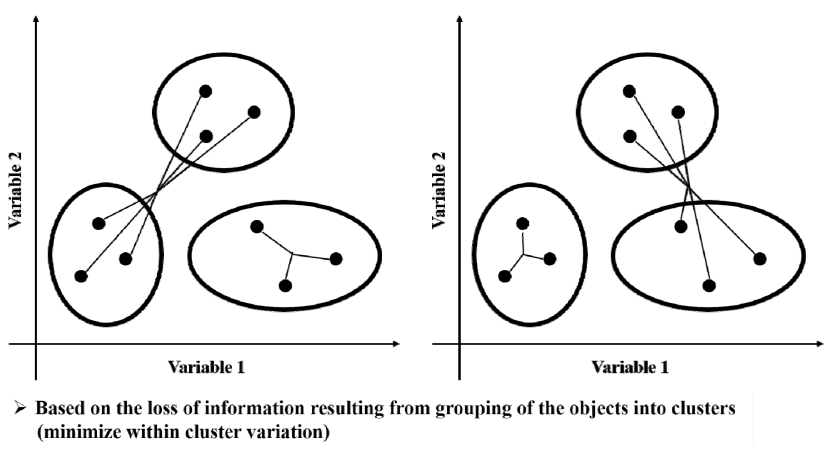

Fig. 2. Ward linkage method.

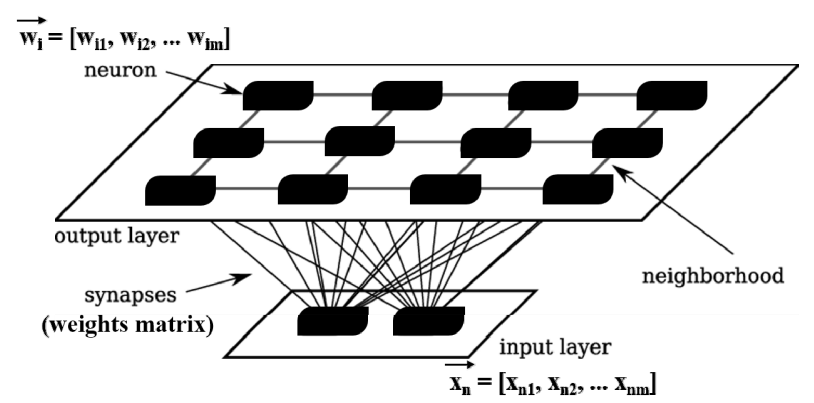

Fig. 3. Architecture of self organizing map.

시각적으로 이해하기 쉬운 특징이 있다.

또한 계층적 군집분석 후, 군집화가 얼마나 잘 되었는지 알 아보기 위해 군집 내부의 유효성 측정을 하였으며, 유효성 측 도로 dunn index, silhouette을 고려하였다. ${ }^{17)}$ dunn index는 같은 군집에 속해있는 두 개체간의 최대거리에 대한 서로 다 른 군집에 속해있는 두 개체간의 최소거리의 비율(ratio)로 정
의되며, 값이 클수록 군집화가 잘 된 것으로 평가된다. dunn index $\left(\mathrm{D}_{\mathrm{i}}\right)$ 는 다음 Eq. (2.6)과 같이 계산할 수 있다.

$$
D_{i}=\frac{\min _{1 \leq i<j \leq n} d(i, j)}{\max _{1 \leq k \leq n} \dot{d}^{\prime}(k)}
$$

$d(i, j):$ the intercluster distance, the distance between cluster $i, j$

$d(k)$ : the intracluster distance of cluster $k$, the distance within cluster $\mathrm{k}$

silhouette은 개체 i가 속해있는 군집 내의 모든 개체들과 $\mathrm{i}$ 사이의 평균거리(a(i))와 개체 $\mathrm{i}$ 가 속해있지 않은 다른 군집 내의 모든 개체들과 $\mathrm{i}$ 사이의 평균거리 중 가장 작은 값(b(i)) 을 이용하여 도출하며, -1 에서 1 사이의 값을 갖는다. silhouette $\left(\mathrm{S}_{\mathrm{i}}\right)$ 는 dunn index와 마찬가지로 값이 클수록 군집화가 잘 되 었다고 판단하며, Eq. (2.7)과 같이 계산할 수 있다.

$$
S_{i}=\frac{b(i)-a(i)}{\max [b(i), a(i)]}
$$

\section{3. 결과 및 고찰}

\section{1. 국가 물환경측정망 수질특성 및 NSFWQ 수질지수}

서울시내 17 개 국가 물환경측정망에 대한 산정된 평균 수 질농도 및 NSFWQI 수질지수는 Table 3과 같다. Table 3에 보듯이, 대부분의 수질측정망 평균 수질은 $\mathrm{BOD}$ 0.5 6.6 $\mathrm{mg} / \mathrm{L}, \mathrm{TP} \quad 0.011 \sim 0.532 \mathrm{mg} / \mathrm{L}$ 로 환경정책기본법 시행령 내

\begin{tabular}{|c|c|c|c|c|c|c|c|c|c|c|c|}
\hline Stream & $\begin{array}{l}\text { BOD } \\
(\mathrm{mg} / \mathrm{L})\end{array}$ & $\begin{array}{c}\text { DO } \\
(\mathrm{mg} / \mathrm{L})\end{array}$ & $\begin{array}{c}\mathrm{FC} \\
\text { (count/100 mL) }\end{array}$ & $\begin{array}{l}\mathrm{NO}_{3}^{-} \\
(\mathrm{mg} / \mathrm{L})\end{array}$ & $\mathrm{pH}$ & $\begin{array}{l}\text { TC } \\
\left({ }^{\circ} \mathrm{C}\right)\end{array}$ & $\begin{array}{c}\mathrm{TP} \\
(\mathrm{mg} / \mathrm{L})\end{array}$ & $\begin{array}{l}\text { Turbidity } \\
\text { (NTU) }\end{array}$ & $\begin{array}{c}\text { TS } \\
(\mathrm{mg} / \mathrm{L})\end{array}$ & WQI & Rating \\
\hline Godeokcheon & 3.0 & 10.2 & 13,501 & 3.427 & 7.8 & 4.5 & 0.156 & 4.8 & 745.2 & 69 & Medium \\
\hline Dorimcheon & 1.4 & 11.2 & 1,237 & 3.091 & 7.8 & 4.3 & 0.067 & 1.6 & 183.1 & 77 & Good \\
\hline Mokgamcheon & 2.6 & 10.0 & 4,314 & 5.530 & 7.7 & 2.3 & 0.155 & 4.0 & 306.0 & 71 & Good \\
\hline Seongnaecheon & 2.9 & 7.5 & 1,637 & 1.444 & 7.6 & 3.9 & 0.084 & 3.6 & 178.8 & 73 & Good \\
\hline Seongbukcheon & 1.6 & 12.5 & 1,035 & 3.049 & 7.7 & 0.7 & 0.038 & 2.0 & 258.2 & 77 & Good \\
\hline Anyangcheon5 & 3.7 & 7.9 & 2,375 & 4.415 & 7.5 & 1.4 & 0.093 & 4.2 & 370.0 & 70 & Good \\
\hline Yangjaecheon & 1.3 & 10.6 & 3,364 & 4.943 & 7.7 & 4.5 & 0.090 & 2.6 & 291.0 & 74 & Good \\
\hline Uicheon & 1.5 & 12.0 & 1,141 & 5.349 & 8.1 & -1.9 & 0.030 & 2.2 & 254.7 & 76 & Good \\
\hline Jeongneungcheon & 1.0 & 13.2 & 2,411 & 5.110 & 8.0 & 2.3 & 0.056 & 1.5 & 300.5 & 72 & Good \\
\hline Jungnangcheon2 & 1.9 & 12.1 & 5,959 & 6.090 & 7.7 & 0.2 & 0.080 & 3.3 & 277.3 & 72 & Good \\
\hline Jungnangcheon3 & 2.0 & 10.3 & 2,460 & 5.425 & 7.8 & 2.2 & 0.059 & 3.6 & 277.4 & 76 & Good \\
\hline Jungnangcheon4 & 6.6 & 7.6 & 42,786 & 7.192 & 7.3 & -1.4 & 0.532 & 4.6 & 310.8 & 64 & Medium \\
\hline Cheonggyecheon1 & 0.5 & 10.8 & 24 & 1.841 & 7.8 & 3.3 & 0.011 & 1.4 & 117.8 & 89 & Good \\
\hline Cheonggyecheon2 & 0.8 & 11.2 & 558 & 1.877 & 7.9 & 2.1 & 0.014 & 1.5 & 125.8 & 82 & Good \\
\hline Cheonggyecheon3 & 1.5 & 11.5 & 703 & 2.075 & 8.0 & 1.6 & 0.040 & 2.1 & 157.1 & 80 & Good \\
\hline Tancheon5 & 3.0 & 8.4 & 5,487 & 5.102 & 7.5 & 1.2 & 0.132 & 2.7 & 316.6 & 72 & Good \\
\hline Hongjecheon & 2.7 & 11.9 & 1,325 & 5.501 & 7.9 & 0.8 & 0.047 & 2.7 & 288.5 & 73 & Good \\
\hline
\end{tabular}

Table 3. The average water quality and indexes for the 17 water quality monitoring networks in Seoul. 
수질 및 수생태계 하천생활환경기준에 따라 BOD II 등급(약 간 좋음) 이상, TP III등급(보통) 이상으로 유기물 및 영양염 류에 의한 오염은 양호한 것으로 나타났다. 수질지수 또한 64 (Medium) 89 (Good)으로 나타났으며, 중랑천4, 고덕천 을 제외하고는 수생생물 서식처, 레저활동이 가능한 친수공 간으로서 가능성을 보이는 등 전반적으로 17 개 국가 물환경 측정망은 모두 양호한 수질을 보였다.

반면 Fig.4에서 보듯이, 중랑천4, 고덕천 등 일부 수질측 정망의 경우 수질이 최악일 때에는 $\mathrm{BOD}$ 의 경우 $22.7 \mathrm{mg} / \mathrm{L}$ (VI등급, 매우 나쁨), $7.1 \mathrm{mg} / \mathrm{L}$ (IV 등급, 약간 나쁨)까지, TP 의 경우 $1.6 \mathrm{mg} / \mathrm{L}$ (VI등급, 매우 나쁨), $0.825 \mathrm{mg} / \mathrm{L}$ (VI등급, 매우 나쁨)까지 악화되어 수질지수는 51 (Medium), 53 (Medium)까지 떨어지는 경우도 발생하였다. 즉, 일부 수질 측정망에서 수질지수가 낮게 나오는 이유는 다른 수질측정 망에 비해 상대적으로 $\mathrm{BOD}$, 탁도, 분원성대장균군 등의 유 기성 오염물질과 미생물 항목이 고농도로 나타나는 등 오염 정도가 다른 수질측정망에 비해 상대적으로 높았기 때문이 라고 판단된다. 특히 중랑천4의 경우에는 대표적 영양염류 인자인 TP도 고농도로 검출되었고, 동시에 수질지수 산정 시, 가중치가 가장 높은 DO (0.17) 항목의 농도는 Fig. 7과 같이 가장 낮아서 전체적으로 수질지수 또한 가장 작게 나 타났다.

계절별로 수질지수 변화를 살펴보아도(Fig. 5), 중랑천4, 고 덕천의 경우, 수질지수가 70 이하(Medium)로 나오는 등 다 른 지점에 비해 좋지 않은 수질이 지속적으로 나타났다. 따 라서 이러한 지점에 대하여 우선적으로 현장조사 및 수질을 악화시키는 원인(하상구조, 하천정비공사, 인근 시설 등)을 찾고, 궁극적으로는 해당되는 하천을 중심으로 오염부하량 저감을 위한 고도처리시설 개선, 하수관거정비사업과 함께 소권역별 유역중심의 물환경체계를 구축하는 등 체계적이고 효과적인 하천수질관리가 필요하다고 판단된다. 한편 강우, 전도현상 등 특히 겨울철의 경우 하천유지 유량이 적어 수질 오염도가 상대적으로 높고, 소량의 오염물질 유입으로도 하 천수질이 악화될 수 있어, 계절 특성에 따라 수질지수가 영 향을 받을 것으로 예상했지만 이와 달리 지점별로 살펴본 계

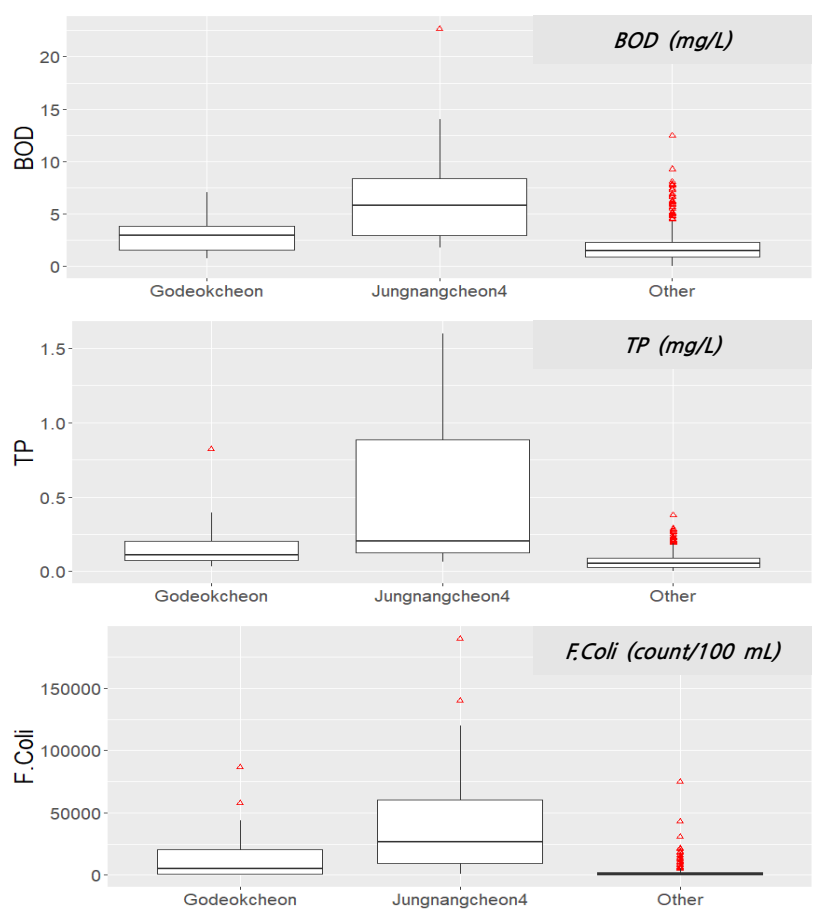

Fig. 4. Boxplot of Godeokcheon and Jungnangcheon4 pollutant concentration changes.

절별 수질지수는 일부 지점(성북천 74 (Good) 83 (Good), 성 내천 71 77)을 제외하고는 지점별로 모두 5 이내의 차이를 보였다. 또한 계절별 평균 수질지수는 봄 74 (62 90), 여름 74 (65 90), 가을 75 (65 91), 겨울 75 (63 87) 등 수질등급 이 모두 ‘Good'으로 나타나 계절별로 큰 차이를 보이지 않는 특징을 확인하였다. 따라서 NSFWQI 수질지수는 계절적인 영향보다는 인위적인 오염원 등에 영향을 크게 받는 것으로 판단된다.

하지만 Fig. 6을 살펴보면, 상대적으로 수질이 취약한 중 랑천4, 고덕천의 경우, 2015년 1월 2016년 6월까지 평균 수 질지수가 각각 60 (Medium), 66 (Medium)에서 2016년 7월 2017년 12월까지의 평균 수질지수는 각각 68 (Medium), 73 (Good)으로 높아지는 등 2016년 하반기부터는 점차 수질개 선이 이루어졌음을 알 수 있었는데, 이는 수질지수 가중치가

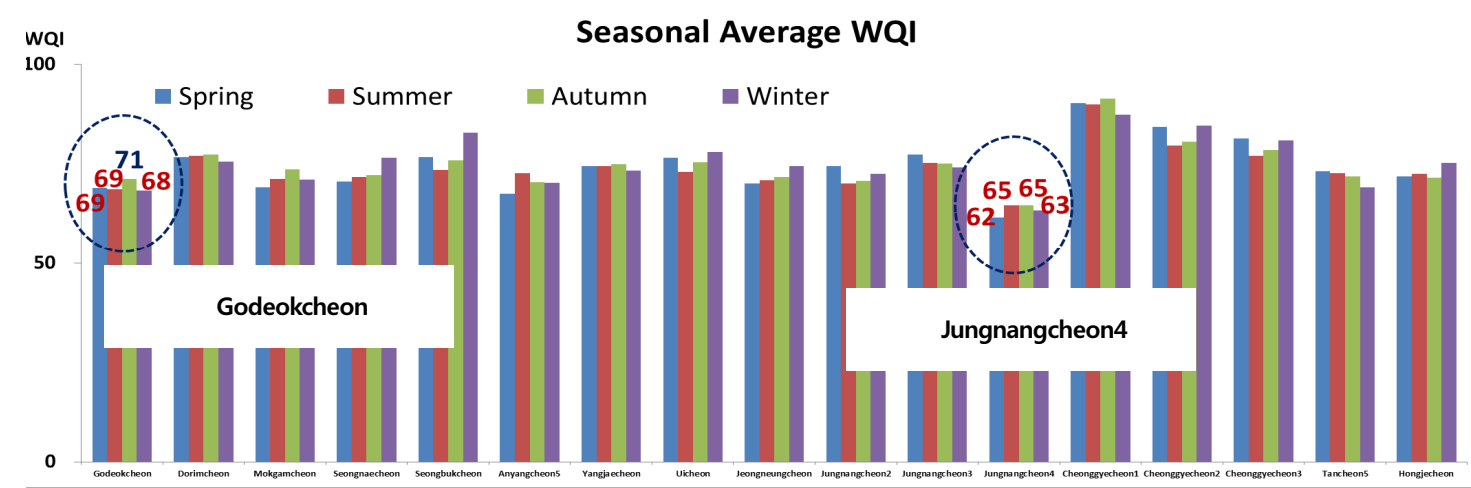

Fig. 5. Seasonal average WQI of 17 water quality monitoring networks in Seoul. 


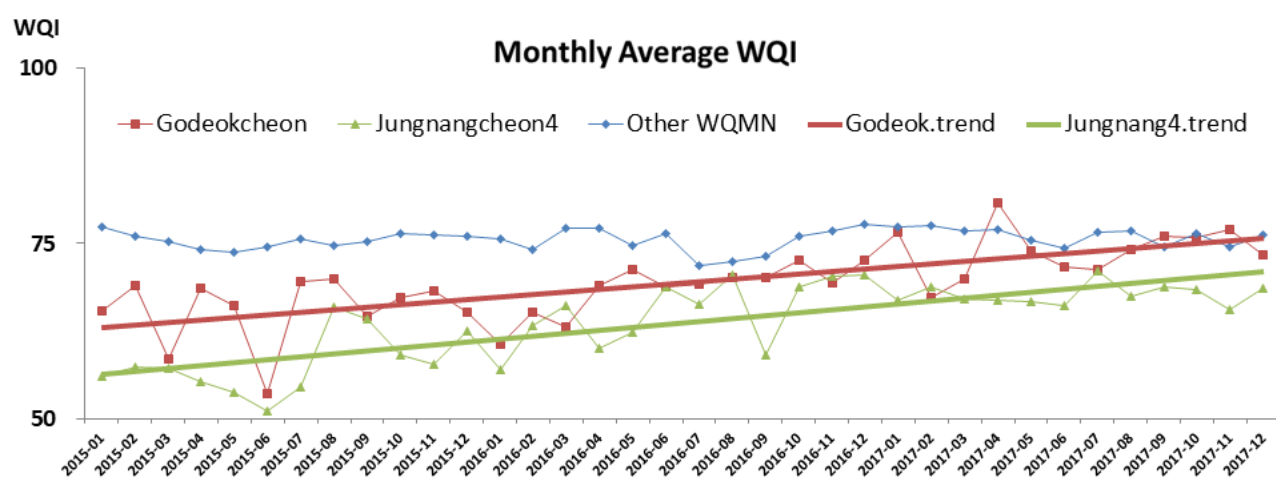

Fig. 6. Monthly average WQI of 2 water quality monitoring networks (Godeokcheon, Jungnangcheon4).
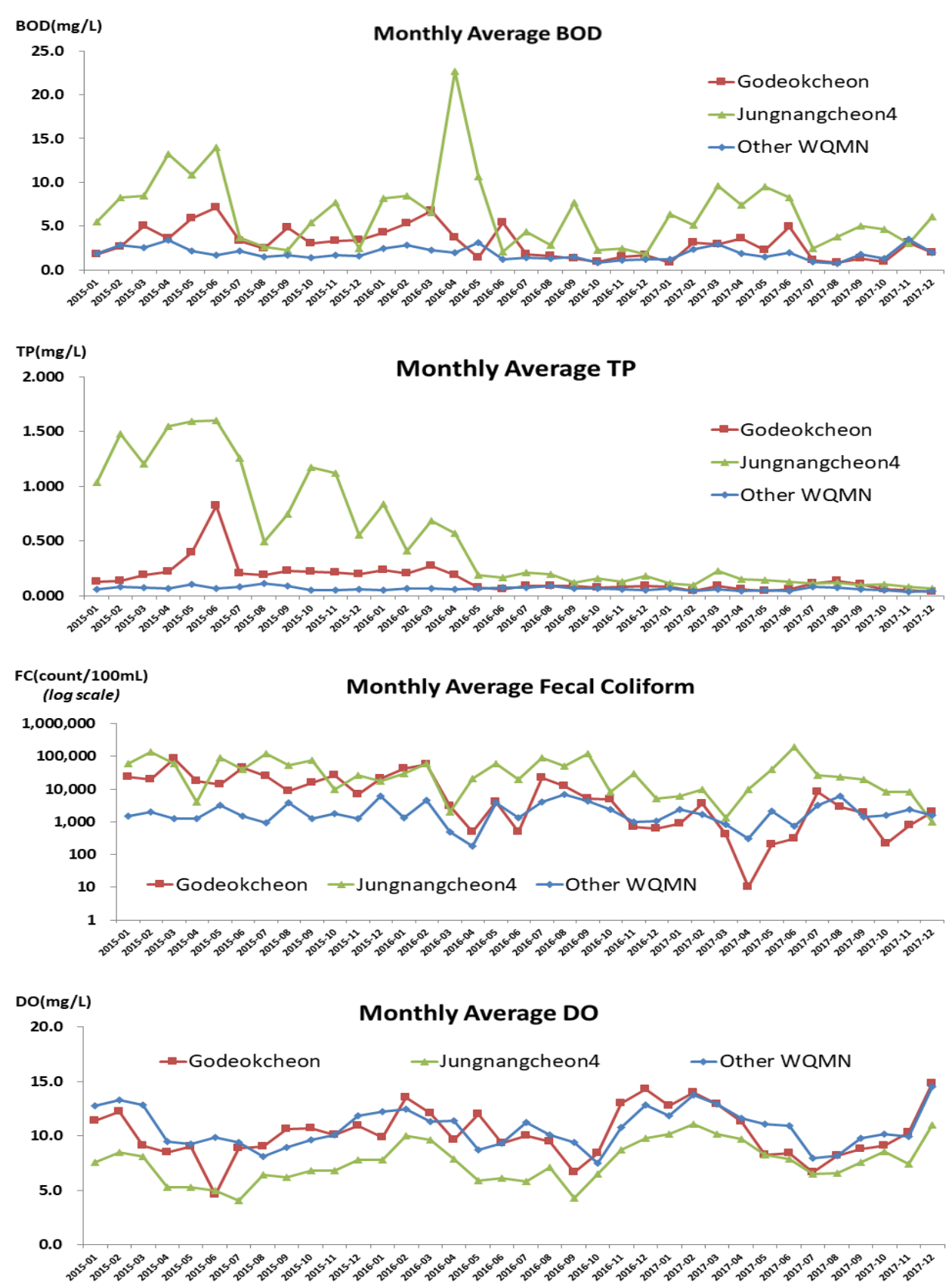

Fig. 7. Monthly average BOD, TP, FC and DO of 2 water quality monitoring networks (Godeokcheon, Jungnangcheon4). 


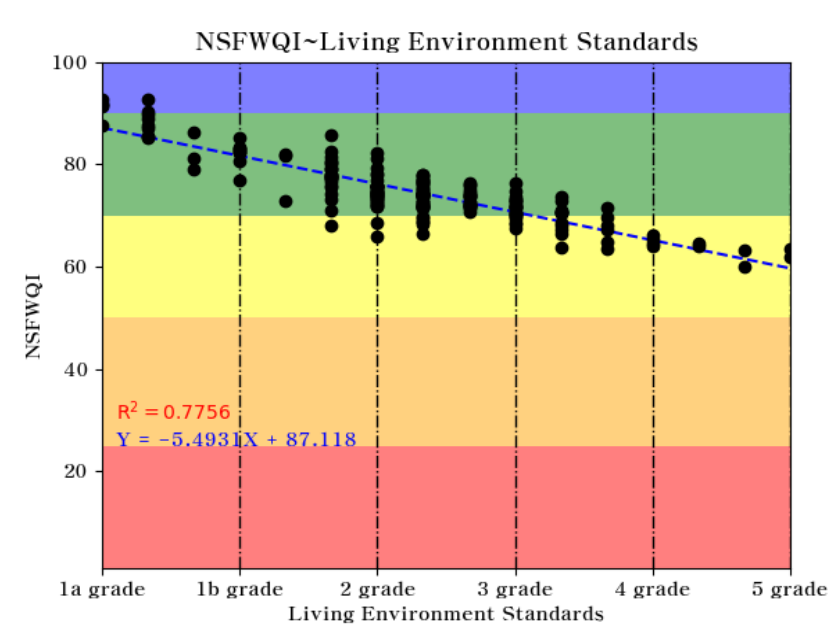

Fig. 8. Comparison of NSFWQI and Living Environment Standards.

상대적으로 높은 오염물질 대표항목 BOD (0.11), TP (0.10), 분원성대장균군(0.16)에 있어서 $\mathrm{BOD}$ 와 달리 $\mathrm{TP}$, 분원성대 장균군 항목의 농도가 전반적으로 감소하였기 때문이라고 판단된다(Fig. 7).

또한 본 연구에서 도출한 NSFWQI 수질지수와 환경기준 에 따른 수질등급과의 상관성 및 연계 가능성을 살펴보았 다. 비교결과, Fig. 8과 같이 $\mathrm{R}^{2}$ (결정계수, Coefficient of determination)이 0.78 로 비교적 높은 상관관계를 가지는 것 으로 확인되었으며, 비정규분포에 따른 Wilcoxon Mann Whitney test 검정결과에서도 유의확률 $p$ 값이 0.2695 로 유 의수준 5\%보다 크게 나타나 두 그룹(NSFWQI 수질지수, 환 경기준에 따른 수질등급체계)간의 뚜렷한 차이를 볼 수 없 었다. 따라서 현재 시행되는 수질등급체계와 NSFWQI 수질
지수는 매칭이 잘 되는 것으로 판단된다.

\section{2. 군집분석}

수질특성에 따라 17 개 국가 물환경측정망을 그룹화하기 위해서 Ward 연결법과 SOM을 이용한 군집분석 결과는 Fig. 9 11과 같다. 우선 Ward 연결법 군집분석 후, 군집화 적절성 척도로서 사용되는 dunn index와 silhouette을 이용 하여 군집화를 평가하였다. 그 결과 17 개 국가 물환경측 정망을 6 개의 그룹으로 나누었을 때 dunn index는 0.48 , average silhouette width는 0.19 로 계산되었다. 여기서 average silhouette width가 0.19 로 작게 나타난 이유는 중랑 천4, 성내천에서 silhouette이 0 (군집 간 경계면에 위치)을 갖는 등 일부 지점에서 아주 작은 값을 나타냈기 때문이며, 비록 average silhouette width는 작지만 음수가 발생하지 않 았고, 특히 가능한 범위에서 다른 개수의 그룹으로 분류할 때보다 값이 높게 나타났기 때문에 군집화가 적정하게 이루 어졌다고 판단하다였다. 또한 $\mathrm{SOM}$ 을 이용한 군집분석 결 과 역시 수질특성에 따라 6 개의 그룹으로 나타내는 등 많은 자료를 빠르고 쉽게 분류할 수 있었다.

1 번째 그룹은 청계천1, 청계천2, 청계천3, 도림천으로 묶 였다. 청계천 1 3의 경우, 같은 줄기의 하천(청계천)이면서 거리상으로 크게 떨어져 있지 않기 때문에 유사한 수질특성 을 보였으며, 특히 평균 수질지수가 모두 80 이상 $(\mathrm{Good})$ 으 로 높게 나타나는 등 주요 수질항목인 $\mathrm{BOD}, \mathrm{TP}$, 분원성대 장균군 등의 오염정도가 낮은 깨끗한 수질특성을 보였다. 2 번째 그룹은 중랑천 하류 지점인 중랑천4로, 이는 중랑천 최말단 지점으로서 $\mathrm{J}$ 물재생센터 방류수도 유입되는 등 한강 본류에 합류하기 이전 지점이라는 특징상 다른 수질측정망

\section{Water Quality Monitoring Networks [Hierarchical Clustering]}

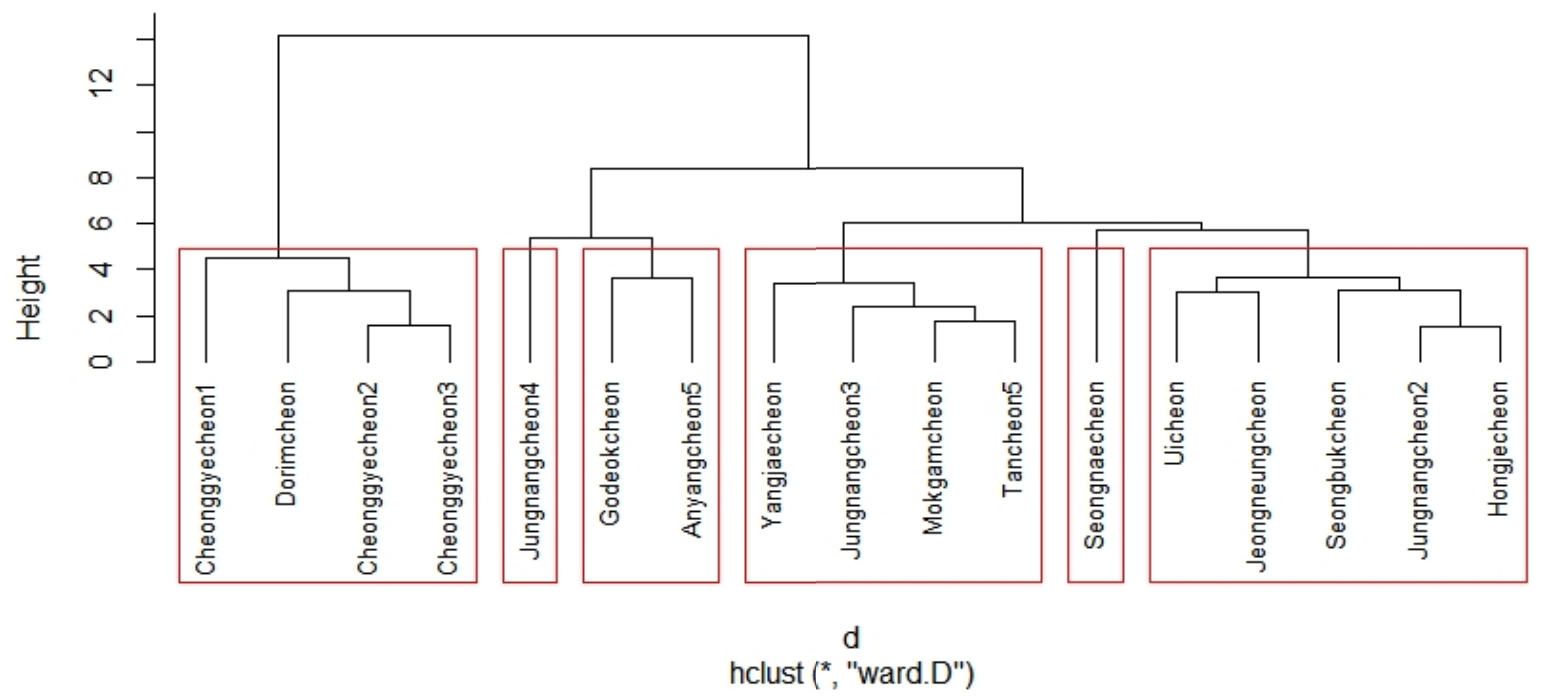

Fig. 9. Hierarchical clustering result for 17 water quality monitoring networks (ward linkage method). 


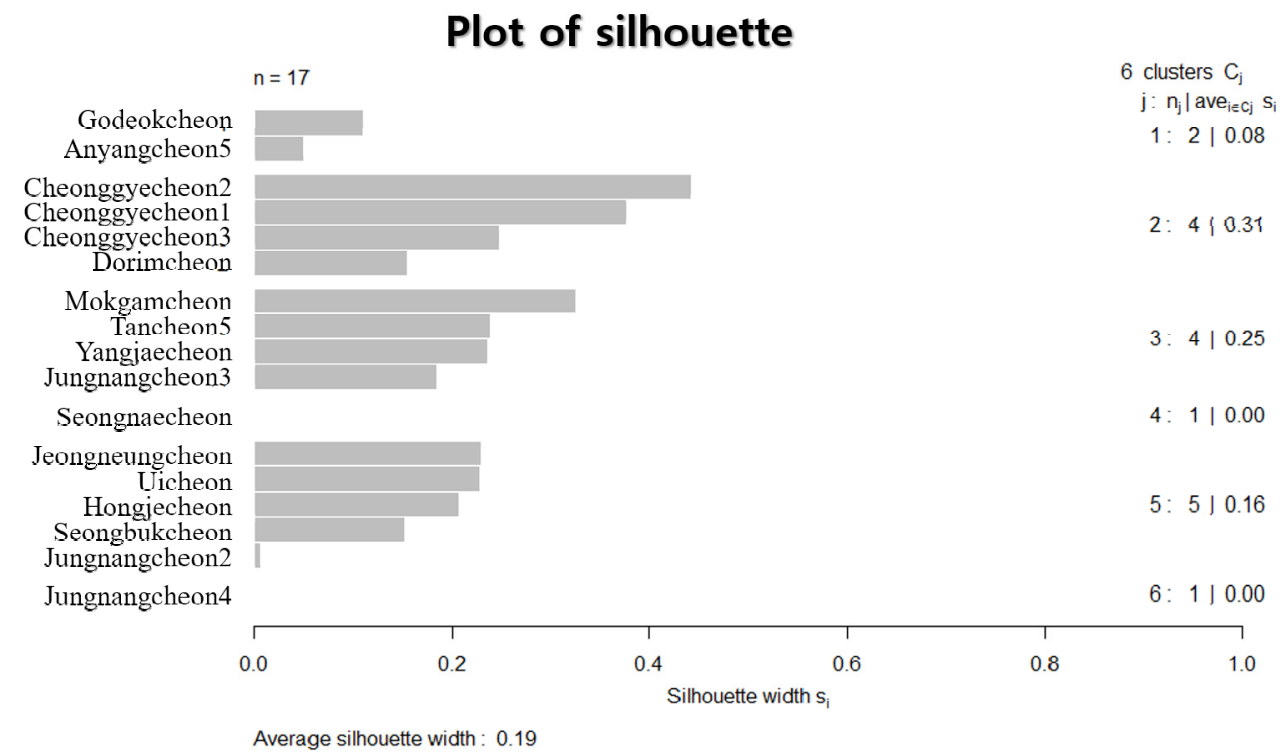

Fig. 10. Plot of silhouette for 17 water quality monitoring networks.

17 Water Quality Monitoring Networks

[Self Organising Map Clustering]

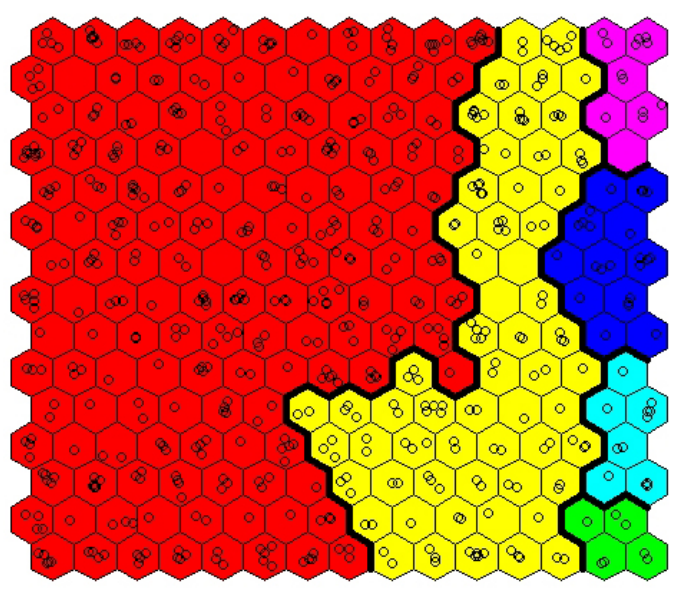

Uicheon

Jeongneungcheon

Seongbukcheon

Jungnangcheon2

Hongjecheon

Cheonggyecheon1

Dorimcheon

Cheonggyecheon2

Cheonggyecheon 3

Yangjaecheon

Jungnangcheon3

Mokgamcheon

Tancheon5

Godeokcheon

Anyangcheon 5

Jungnangcheon 4

Seongnaecheon

Fig. 11. SOM clustering result for 17 water quality monitoring networks.

에 비해 전반적으로 유기물, 분원성대장균군 등의 수질오염 정도가 높았다. 3 번째 그룹은 고덕천, 안양천 5 로, 각각의 평 균 수질지수는 고덕천 69 (Medium), 안양천5 70 (Good)으 로, 유기물 지표항목인 BOD 평균농도는 각각 $3.0 \mathrm{mg} / \mathrm{L}, 3.7$ $\mathrm{mg} / \mathrm{L}$ 로 나타나는 등 이 역시 각각의 줄기 하천인 고덕천, 안양천의 하류 지점이라는 특징 때문에 수질특성이 좋지 않 은 것으로 판단된다. 반면에 4 번째 그룹은 양재천, 중랑천3, 목감천, 탄천 5 로 구성되어 있는데, 탄천 5 를 제외하고는 줄 기 하천인 탄천, 중랑천, 안양천의 최말단 지점(중랑천4, 안 양천5)보다 상류에 위치한다는 공통된 특징을 가지고 있다. 5 번째 그룹은 고립된 군집으로서 성내천으로 나타났으며, 6 번째 그룹은 우이천, 정릉천, 성북천, 중랑천 2 , 홍제천으로 그룹화 되었다. 특히 중랑천 2 와 우이천의 경우, 평균 수질지
수는 각각 $72(\mathrm{Good}), 76(\mathrm{Good})$ 으로, 주요 수질항목인 DO 평균농도는 $12.1 \mathrm{mg} / \mathrm{L}, 12.0 \mathrm{mg} / \mathrm{L}$ 로, 유기물 오염지표인 BOD 평균농도는 $1.9 \mathrm{mg} / \mathrm{L}, 1.5 \mathrm{mg} / \mathrm{L}$ 로, 영양염류 인자인 $\mathrm{TP}$ 평균농도는 $0.080 \mathrm{mg} / \mathrm{L}, 0.030 \mathrm{mg} / \mathrm{L}$ 로 수질특성이 유사 하게 나타났는데, 이는 두 지점이 $7 \mathrm{~km}$ 이상으로 떨어져 있 지만, 줄기 하천이 중랑천으로 같고, 중랑천 2 와 우이천 사이 에 오염원으로서 크게 작용하는 것이 없기 때문이라고 판단 된다.

따라서 본 연구에서와 같이 Ward 연결법과 SOM을 이용 한 군집분석 결과 등을 적극 활용함으로써 많은 자료를 빠 르고 쉽게 분류하여 내재되어 있는 정보를 추출할 수 있었 으며, 이를 통해 적은 수질항목으로도 전체적인 대상지점의 수질특성을 파악할 수 있었다. 


\section{4. 결 론}

본 연구에서는 서울시내 17 개 수질측정망(지천)을 대상으 로, 2015 2017년 최근 3년 동안 매월 생산되는 DO, 분원성 대장균군, $\mathrm{pH}, \mathrm{BOD}, \mathrm{TP}$ 등 9 개 항목을 이용하여 최근 종합 적인 수질평가에 활용되고 있는 수질지수를 산정하고, 이를 활용하여 수질특성에 따라 군집분석을 실시하는 등 향후 서 울시 하천수질관리를 위한 기초자료를 제공하고자 하였으 며, 주요 연구결과는 다음과 같다.

1) 최근 3 년간 17 개 국가 물환경측정망의 수질을 살펴보면, 대부분의 수질측정망 수질은 평균적으로 수질 및 수생태계 하천생활환경기준에 따라 $\mathrm{BOD} \Pi \mathrm{I}$ 등급(약간 좋음) 이상, TP III등급(보통) 이상으로 나타났고, 수질지수 또한 64 (Medium) 89 (Good)으로 나타나는 등 전반적으로 수생생물 서식처, 친수공간이 가능한 수준의 양호한 수질을 보였다.

2) 유기성 오염물질과 미생물 항목이 고농도로 나타나는 등 오염정도가 다른 수질측정망에 비해 상대적으로 높은 중 랑천4, 고덕천 등 일부 수질측정망의 경우 2016년 하반기부 터는 전반적으로 유기물 지표항목, 미생물 항목, 영양염류 가 감소 또는 안정적인 추세를 보여, 수질지수가 점점 높아 지는 경향을 보이고 있지만, 초기강우에 따른 비점오염원 유입, 물재생센터에서의 방류수 유입 등의 다양한 수질저하 원인이 존재하기 때문에 지속적인 하천수질관리가 필요하 다고 판단된다.

3) 강우, 전도현상, 유량변동 등 계절 특성에 따라 NSFWQI 수질지수가 영향을 받을 것으로 예상했지만 이와 달리 계절별 로 큰 차이를 보이지 않는 특징을 통해 NSFWQI 수질지수는 계절적인 영향보다는 인위적인 오염원 등에 영향을 크게 받는 것으로 판단된다.

4) NSFWQI 수질지수와 환경기준에 따른 수질등급을 비 교·분석한 결과, $\mathrm{R}^{2}$ 이 0.78 로 비교적 높은 상관관계를 갖고, 두 그룹간의 뚜렷한 차이를 볼 수 없는 등 현재 시행되는 수 질등급체계와 NSFWQI 수질지수는 매칭이 잘 되는 것으로 판단된다.

5) 17 개 국가 물환경측정망을 대상으로 Ward 연결법 및 $\mathrm{SOM}$ 을 이용한 군집분석 결과, 수질특성에 따라 크게 6개 의 그룹으로 나누었으며, 이를 통해 많은 자료를 빠르고 쉽 게 분류하여 군집별 특성을 파악하고, 특히 소권역별 유역 중심의 물환경체계를 구축하는데 향후 체계적이고 효과적 인 하천수질관리에 기초자료로 활용될 수 있을 것으로 판단 된다. 동시에 시민들의 알권리 충족에 부합될 수 있는 형태 의 이해하기 쉽고, 종합적인 수질정보를 제공할 것으로 기 대한다.

하천으로의 오염물질 유입은 그 종류와 양이 증가되고 있 으며, 이러한 상황 속에서 하천을 수자원으로서 지속적으로 활용하기 위해서는 하천수질을 체계적으로 관리하기 위한 오염원 관리가 무엇보다 중요하다. 본류 및 지류·지천의 오
염원 관리를 위해 설치된 수질측정망에서는 다양한 수질항 목들을 측정하고 있지만, 개별항목을 측정·분석하는 것만으 로는 체계적이고 종합적으로 하천수질을 평가하는 것은 어 렵다. 따라서 본 연구와 같이 하천수질상태를 쉽게 이해하 기 위해서 복잡하고 다양한 수질정보를 간단한 지표로 변환 한 수질지수가 필요하다. 이를 통해 하천의 종합적인 수질 상태를 파악하고, 다른 하천과의 직관적인 평가와 비교가 가능하게 되어 상수원 관리, 하천정비사업, 고도처리시설 개선 등 하천수질관리 관련 정책 효과 및 예측을 쉽게 할 수 있다. 또한 일부 단일항목만을 이용해 평가함으로써 사 용자가 각 측정 항목 중 일부 불리한 항목을 제외하고 자신 의 목적에 적합하게 수질을 평가해온 것도 피할 수 있으며, 동시에 수질상태에 관하여 전문가와 비전문가간의 의사소 통을 원활하게 할 수 있다. 특히 우리나라와 같이 전국적으 로 수계 및 기후특성이 비슷하고 다양한 용도의 용수수요가 동일한 지점에서 이루어질 경우 전국적으로 적용 가능한 종 합적인 수질지수의 개발과 기존에 널리 사용되고 있는 수질 지수 이용은 바람직하다고 판단된다. 이와 함께 수질특성에 따른 군집화 결과는 향후 서울시 하천수질관리를 위한 기초 자료로 활용될 수 있을 것으로 기대한다.

\section{References}

1. Y. J. Kim, B. S. Gal, J. B. Park, S. H. Kim, T. H. Im, Classification of Nakdong river tributaries under priority management based on their characteristics and water quality index, J. Korean Soc. Environ. Eng., 40(2), 73-81(2018).

2. T. Shweta, S. Bhavtosh, S. Prashant, D. Rajendra, Water quality assessment in terms of water quality index, Am. J. Water Resour., 1(3), 34-38(2013).

3. S. Dutta, A. Dwivedi, M. S. Kumar, Use of water quality index and multivariate statistical techniques for the assessment of spatial variations in water quality of a small river, Environ. Monit. Assess., 190(12), 1-17(2018).

4. I. Gupta, A. Kumar, C. Singh, R. Kumar, Detection and mapping of water quality variation in the Godavari river using water quality index, clustering and GIS techniques, Journal of Geographic Information System, 7(2), 71-84(2015).

5. K. Yogendra, E. T. Puttaiah, Determination of water quality index and suitability of an urban waterbody in Shimoga Town, Karnataka, The $12^{\text {th }}$ World Lake Conference, pp. 342-346(2008).

6. C. C. Kim, Beginning Data Science in R, Slow\&Steady, Seoul, Korea, pp. 191-193(2018).

7. Ministry of Environment, Water Pollution Standard Method(2017).

8. Ministry of Environment, Quality Standard for Drinking Water(2017).

9. R. M. Brown, N. I. McClelland, R. A. Deininger, R. G. 
Tozer, A water quality index-do we dare?, Water Sew. Works, 117, 339-343(1970).

10. Water Quality Index Protocol, http://www.pathfinderscience. net/stream/cproto4.cfm, October(2019).

11. Calculating NSF Water Quality Index, http://home.eng.iastate. edu/ dslutz/dmrwqn/water_quality_index_calc.htm, October (2019).

12. J. J. Packman, K. J. Comings, D. B. Booth, Using turbidity to determine total suspended solids in urbanizing streams in the Puget Lowlands, Canadian Water Resources Association annual meeting, pp. 158-165(1999).

13. A. F. Rusydi, Correlation between conductivity and total dissolved solid in various type of water: A review, IOP Conf. Series: Earth and Environmental Science, 118, 012019(2018).

14. Calculating Oxygen Percent Saturation and Comments on Controls of Oxygen Saturation, https://projects.ncsu.edu/cals/ course/zo419/oxygen.html, February(2019).

15. Ministry of Environment, The Enforcement Decree of the Framework Act on Environmental Policy(2019).

16. B. C. Paik, C. K. Kim, T. R. Kim, A study on the pattern analysis of correlation between the river flow and water quality using a SOM (Self Organizing Maps) technique, Journal of Korean Society of Urban Environment, 11(2), 153-160(2011).

17. J. H. Kim, Y. S. Ko, A comparison of cluster analyses and clustering of sensory data Hanwoo bulls, The Korean Journal of Applied Statistics, 22(4), 745-758(2009).

\section{Authors}

\section{Jinhyo Lee}

Water Environment Research Department, Seoul Metropolitan Government Research Institute of Public Health and Environment, Department of Environmental Engineering, University of Seoul, Researcher, ORCID(1) 0000-0002-2989-1682

\section{Hyunju $\mathrm{Ha}$}

Water Environment Research Department, Seoul Metropolitan Government Research Institute of Public Health and Environment, Researcher, ORCID(1) 0000-0002-2202-7939

\section{Manho Lee}

Water Environment Research Department, Seoul Metropolitan Government Research Institute of Public Health and Environment, Team Leader, ORCID(i) 0000-0001-8894-9605

\section{Mokyoung Lee}

Water Environment Research Department, Seoul Metropolitan Government Research Institute of Public Health and Environment, Director, ORCID (1) 0000-0001-7227-5415

\section{Taeho Kim}

Department of Environmental Engineering, University of Seoul, Researcher, ORCID(1) 0000-0003-2714-5165

\section{Yoonkyung Cha}

Department of Environmental Engineering, University of Seoul, Professor, ORCID (다 0000-0001-9638-9476

\section{Jayong Koo}

Department of Environmental Engineering, University of Seoul, Professor, ORCID 시 0000-0001-8313-3033 